\title{
Qualitative and quantitative analysis of biological samples from non-metastatic breast cancer patients
}

\author{
Ehab I. Mohamed ${ }^{1 *}$, Moustafa H. Moustafa ${ }^{1}$, Marwa A. Mohamed², El-Sayed I. Awad ${ }^{3}$, Hala K. Maghraby4, Taddese W. Godeto ${ }^{5,6}$ and \\ Brian M. Ross ${ }^{5}$
}

*Correspondence: eimohamed@yahoo.com ; ehab.abdo@alexu.edu.eg

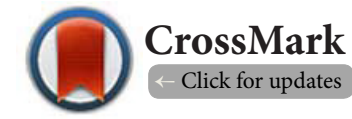

\begin{abstract}
'Department of Medical Biophysics, Medical Research Institute, Alexandria University, Alexandria, Egypt. ${ }^{2}$ Department of Chemical Pathology, Medical Research Institute, Alexandria University, Alexandria, Egypt. ${ }^{3}$ Department of Pathology, Medical Research Institute, Alexandria University, Alexandria; Egypt.

${ }^{4}$ Department of Experimental and Clinical Surgery, Medical Research Institute, Alexandria University, Alexandria, Egypt.

${ }^{5}$ Northern Ontario School of Medicine, Lakehead University, Ontario, Canada.

${ }^{6}$ Ministry of the Environment and Climate Change, Ontario, Canada.
\end{abstract}

\begin{abstract}
Background: Breast cancer (BC) is one of the most common non-skin cancers in women and the fifth most common cause of cancer death worldwide. Both the prognosis and survival rate of $\mathrm{BC}$ patient improve considerably if the disease is discovered at an early stage.

Methods: In the present study, we analyzed qualitatively and quantitatively volatile organic compounds (VOCs) in the headspace over urine, blood and tissue samples to identify VOCs characteristic for diagnosing BC. The study comprised 150 women with non-metastatic BC Stage II and an equal number of age-matched Healthy Controls (HC). Collected urine, blood and BC tissue samples were analyzed using the Electronic Nose (E-Nose) and Selected Ion Flow Tube-Mass Spectrometry (SIFT-MS) techniques.

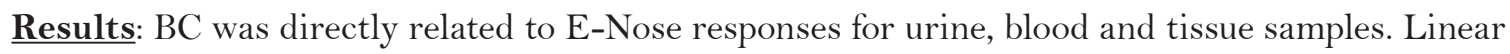
Discriminant Analysis showed separate clusters for urine, blood and tissue sample for BC patients and HC participants, where the first two principal components explained more than $98.84 \%$ of the variance in signals with no false-positive (HC participants) or false-negative (BC patients) results.

Conclusions: SIFT-MS showed the expression of 10 aldehydes in tissue specimens and blood samples for $\mathrm{BC}$ and $\mathrm{HC}$ participants, of which pentanal, hexanal and decanal levels were mutually lower or higher, which means that their presence in the headspace of VOCs is specific for both blood samples and tissue specimens. This provides rationale for developing diagnostic tests for $\mathrm{BC}$ based on altered trace VOCs concentrations using the relatively inexpensive, easy-to-use, portable, and non-invasive E-Nose technology.
\end{abstract}

Keywords: Breast cancer, electronic nose, selected ion flow tube-mass spectrometry, principal components analysis, linear discriminant analysis

\section{Introduction}

Breast cancer $(B C)$ occurs in the epithelium lining the ducts and lobules of breast tissues. It afflicts both men and women, although male $B C$ is rare [1]. $B C$ is considered the most common type of non-skin cancer in women and the fifth most common cause of cancer death worldwide [2]. In 2012, BC was estimated to have affected a total of 1,671,149 new cases, which accounted for $25 \%$ of all new cancer cases in the world (crude rate: $47.8 / 10^{5}$ individuals), and caused 521,907 deaths worldwide (crude rate: $14.7 / 10^{5}$ individuals) [2,3]. According to the National Population-Based Registry Program of Egypt 2008-2011, BC is the most prevalent cancer among Egyptian women, representing $15.41 \%$ of total cancer cases with an age-standardized rate (ASR) of $24.3 / 10^{5}$ individuals ( $32.04 \%$ and $48.8 / 10^{5}$ for women and $0.51 \%$ and $0.9 / 10^{5}$ for men; respectively) [4]. Although treatments are available including 
surgery, drugs (hormonal therapy and chemotherapy), and radiation, both the prognosis and survival rate of $\mathrm{BC}$ patient improve considerably if the disease is discovered at an early stage, when the tumor has not metastasized. Indeed, early detection and optimal treatment results in a 10-year disease free survival rate of $98 \%$ compared to $10 \%$ for those diagnosed late in the progression of the disease [5].

Cancer growth has been shown to be accompanied by gene and/or protein changes inducing lipid peroxidation of the cell membrane species, which leads to the emission of volatile organic compounds (VOCs) $[6,7]$. The Electronic Nose (E-Nose) technology has been used for detecting a wide variety of VOCs in diagnostics, among others, for detecting changes in VOCs in breath samples associated with lung, breast, colon, prostate, and head and neck cancers; in the blood of women with ovarian carcinoma and patients with leukemia; as well as in urine of lung cancer patients [7-9]. E-Nose is an electronic device, which comprises an array of partially specific chemical sensors and an appropriate pattern-recognition system, capable of recognizing simple or complex odors [9]. It is intended to perceive odors and/or flavors, like the human olfactory system, as a global fingerprint rather than identifying and quantifying specific VOCs [7-9]. Thus, the ENose cannot determine which specific VOCs are producing the change in sensor outputs, which is to be complemented with a quantitative technique that can identify the VOCs'volatome' for better understanding the likely biological basis for an E-Nose based test, an important issue effecting adoption of such a procedure for routine clinical use.

Selected Ion Flow Tube-Mass Spectrometry (SIFT-MS) technology has proven accuracy for identifying and quantifying low atomic mass VOCs [10], where VOCs present in a sample are introduced into the flow tube at a precisely controlled rate to react with reagent ions. This reaction results in the formation of particular product ions, which are identified and quantified by a quadrupole mass spectrometer and particle multiplier. Furthermore, when the reaction rate constants are known, ion count rates can be converted into VOCs concentrations without the need to use calibration standards. Since SIFT-MS does not use a chromatographic separation step it is suited to the simultaneous quantification of many different chemical classes and hence works well as a broad-screening tool for VOCs analysis. This technology has been employed for the detection of dangerous levels of fumigants and toxic industrial chemicals in shipping containers, analysis of flavor compounds in various foods such as cheese, chocolate and chewing gum; analysis of hydrocarbons for oil and gas exploration; screening workers urine to monitor toxicity levels; and research into non-invasive disease diagnosis through breath analysis [11].

As such, the major objective of this study was to qualitatively and quantitatively analyze, using both the E-Nose and SIFT-MS techniques, VOCs in the headspace over urine, blood and tissue samples from pathologically confirmed $B C$ patients and Healthy Control (HC) participants to identify VOCs, which are of potential use for diagnosing BC.

\section{Subjects and methods \\ Subjects}

The study population was comprised of 150 women (age range: $24-60$ year, and mean age $\pm S D: 51.12 \pm 10.35$ years) recently diagnosed with non-metastatic BC Stage I-III, who were referred to the Department of Experimental and Clinical Surgery, Medical Research Institute, Alexandria University, Alexandria, Egypt; for surgery. Women diagnosed with BC Stage IV and/or any other confirmed malignancy or chronic disease (e.g., diabetes, liver encephalopathy, autoimmune diseases, etc.), were excluded from the study protocol. Another 150 age-matched healthy women (age range: $24-59$ and mean age: $49.91 \pm 10.75$ year) formed the HC group.

All recruited women were asked to freely volunteer to the study; instructed about the study aim, procedures and benefits; and provided a written informed consent prior to their inclusion in the study. The Ethics Committee of the Medical Research Institute, Alexandria University; approved the study protocol.

\section{Methods}

\section{Clinical Diagnosis and Breast Cancer Staging}

All participants were subjected to complete history taking and thorough physical examination by expert physicians and were asked to complete a questionnaire to determine BC family history, Diabetes Type II, Hypertension, Menstruation Status, and Number of Children. Clinical diagnosis and BC staging were confirmed on basis of findings by physical examination, imaging studies, operative findings and pathologic examination of the breast or other tissues at the Pathology Department, Medical Research Institute, Alexandria University, Alexandria, Egypt.

\section{Sample Collection}

Urine, blood (nearly $2 \mathrm{ml}$ ) and BC tissue samples were collected in duplicates from all participants at the Hospital of the Medical Research Institute, Alexandria University, Alexandria, Egypt; in sterile containers or vacuum tubes (GD, Biomedica Alex Co., Alexandria, Egypt) and were tagged with a random number identifying the participant woman for the E-Nose and SIFT-MS analyses.

\section{Electronic Nose}

First container/tube samples were analyzed at the Medical Biophysics Department, Medical Research Institute, Alexandria University, Alexandria, Egypt; using a commercially available portable E-Nose (PEN3, Airsense Analytics GmbH, Schwerin, Germany) with an array of 10 different metal-oxide sensors. The headspace gases over urine, blood and tissue samples of each sealed tube was carried by the carrier gas (i.e., dry air) to the sensors array through the inlet at a rate of $400 \mathrm{ml} /$ 
Mohamed et al., Breast Cancer Reports 2017,

min. Solenoid valves alternately switch the pure carrier gas and the headspace sample vapor, and the difference in the sensor output was recorded.

Following a $50 \mathrm{~s}$ flushing time and a $10 \mathrm{~s}$ zero point trim time; to bring signals to baseline; periods each, sealed containers/tubes were connected subsequently to the E-Nose inlet through Teflon tubing ( $3 \mathrm{~mm}$ internal diameter) to a long lure-lock needle (size 20G) perforating the seal of the container/tube, for a $60 \mathrm{~s}$ measurement period. A second short needle was also inserted through the seal to allow room air into the container/tube. During the flushing period, sensors were rinsed with carrier gas to return signals back to their baseline $\left(G / G_{0}=1\right)$. All measurements were repeated twice and values of the 10-sensor stable response patterns in the plateau region at $50 \mathrm{~s}$ (shown by the Red Arrow of Figure 1), were extracted and further analyzed, as we detailed earlier [9].

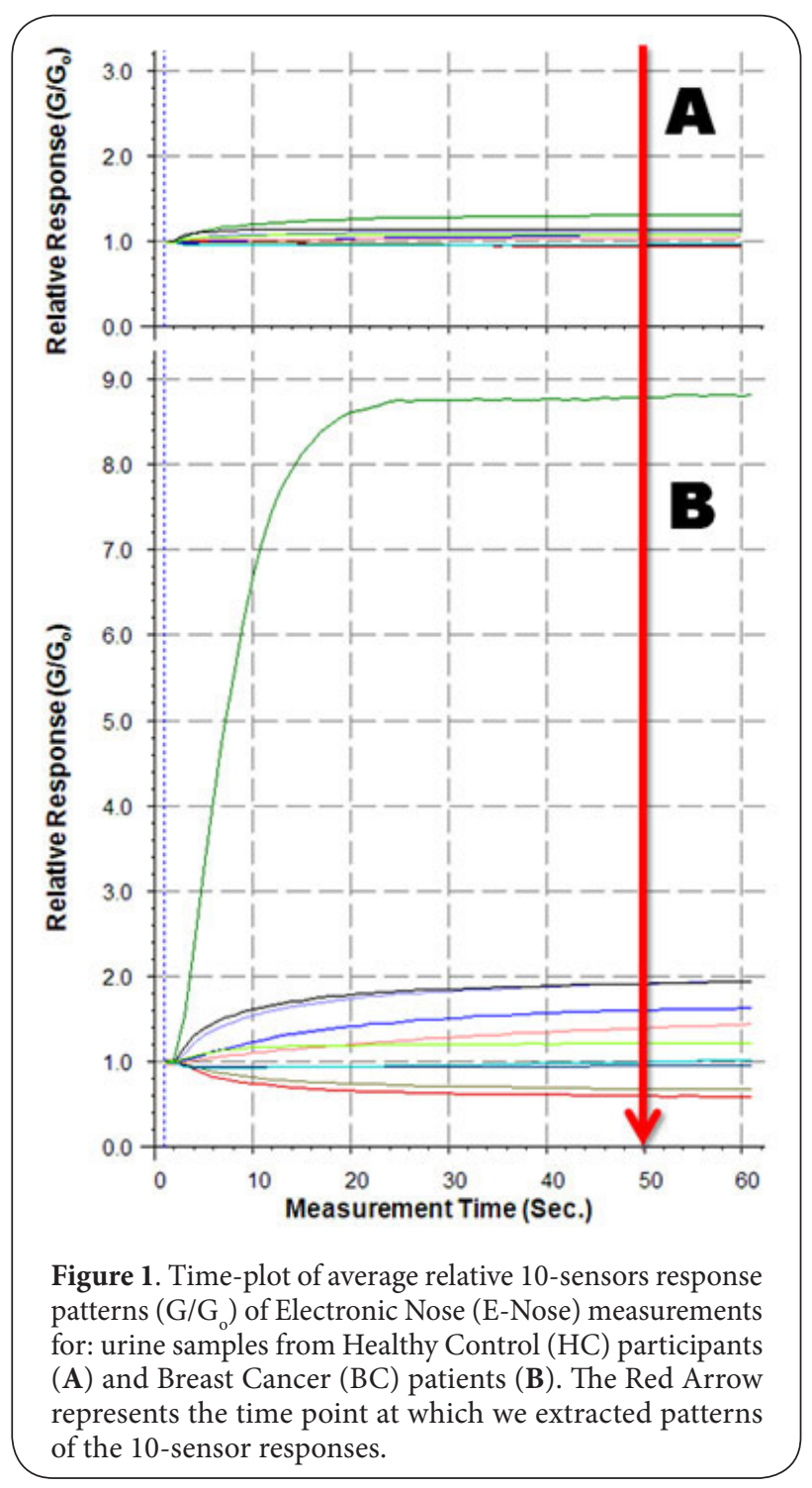

Selected Ion Flow Tube-Mass Spectrometry (SIFT-MS) Blood and tissue, but not urine, samples of the same participant women, were sent frozen in dry ice to be investigated using a Profile 3 SIFT-MS (Instrument Science, Crewe, UK) at the Northern Ontario School of Medicine, Lakehead University, Ontario, Canada. SIFT-MS quantifies the charged products resulting from the reactions between trace gases and various precursor ions (e.g., $\mathrm{H}_{3} \mathrm{O}^{+}, \mathrm{NO}^{+}$and $\mathrm{O}_{2}^{+}{ }^{+}$). lons are mixed with trace gases in a fast flowing stream of helium in flow tube at one Torr and $300 \mathrm{~K}$ to form characteristic ions quantified using a combination of a quadrupole mass analyzer and ion counting system. The routinely used inlet sampling flow rate was 0.2 Torr L.S with gases entering the instrument via a heated $\left(100^{\circ} \mathrm{C}\right)$ Teflon tube $\left(1 / 16^{\prime \prime}\right.$ internal diameter) using negative pressure. Knowledge of the reaction rate coefficient allows for calculating the absolute concentration of trace gases in real time with detection limits in the single digit PPBV or high PPTV range.

The instrument was allowed to warm up between 30 minutes and 1 hour before tuning of the mass filter and source to optimize precursor ion counts and precursor ion purity by a combination of changing the ion source pressure, altering the injected $\mathrm{m} / \mathrm{z}$ setting or altering the ion energy setting of the mass filter. In addition, the mass discrimination and mass accuracy for the downstream mass spectrometer was routinely checked. Purity of the precursor ions was routinely evaluated and was observed to be higher than $99 \%$, with precursor ion count rates being approximately 600,000 for $\mathrm{H}_{3} \mathrm{O}^{+}$(including hydrates), 500,000 for $\mathrm{NO}^{+}$and 500,000 for $\mathrm{O}_{2}^{+*}$.

The concentrations of individual compounds were measured using the multi-ion monitoring mode of the instrument, which quantified the count rates of the appropriate precursor and product ions, as shown in Table 1. Trace gas concentrations were calculated as described with the effects of ion diffusion taken into account using a calculated rather than empirical correction, as we previously described in detail [19].

\section{Data analysis}

All E-Nose measurements were analyzed using the principal components analysis (PCA) and linear discriminant analysis (LDA) techniques for linearly transforming data from the 10-dimensional sensor responses dataset to a two-dimensional coordinate system. PCA is an algorithm that ignores class labels, aiming to find the principal components that maximize the variance in a dataset. PCA is theoretically the optimum transform for given data in least square terms, where the greatest variance by any projection of the data comes to lie on the first coordinate, which is called the principal component \#1; and the second greatest variance on the second coordinate, which is called the principal component \#2. In contrast, LDA computes the linear discriminants representing the axes and maximizing the separation between multiple classes. LDA is also closely related to PCA in that they both look for linear combinations of variables that best explain the data 
Mohamed et al., Breast Cancer Reports 2017, http://www.hoajonline.com/journals/pdf/2057-1631-4-3.pdf

Table 1. Precursor and product ions (with the multiplier value for each ion), and the reaction rate coefficient used for trace gas analysis using Selected Ion Flow Tube-Mass Spectrometry (SIFT-MS).*

\begin{tabular}{|c|c|c|c|c|}
\hline Compound & $\begin{array}{l}\text { Precursor Ion } \\
\text { [Name }(m / z)]\end{array}$ & $\begin{array}{l}\text { Product Ions } \\
{[\mathrm{m} / z \text { (multiplier) }]}\end{array}$ & $\begin{array}{l}\text { React. Rate Coeff. } \\
\left(\mathrm{cm}^{3} \cdot \mathrm{s}^{-1}\right)\end{array}$ & Reference \\
\hline Methanol & $\mathrm{H}_{3} \mathrm{O}^{+}(19,37,55,73)$ & $31(1), 51(1), 69(1)$ & $2.7 \times 10^{-9}$ & Spaněl\& Smith (1997) [12] \\
\hline Ethanol & $\mathrm{NO}^{+}(30,48)$ & $45(1)$ & $1.2 \times 10^{-9}$ & Spanĕl\& Smith (1997) [12] \\
\hline Propanol & $\mathrm{NO}^{+}(30,48)$ & $59(1)$ & $2.3 \times 10^{-9}$ & Spanĕl\& Smith (1997) [12] \\
\hline Acetic Acid & $\mathrm{NO}^{+}(30,48)$ & $90(1)$ & $0.9 \times 10^{-9}$ & Spaněl\& Smith (1998a) [13] \\
\hline PropanoicAcid & $\mathrm{H}_{3} \mathrm{O}^{+}(19,37,55,73)$ & $73(-0.008), 75(1), 93(1), 111(1)$ & $2.7 \times 10^{-9}$ & Spanĕl\& Smith (1998a) [13] \\
\hline Hydrogen Sulphide & $\mathrm{H}_{3} \mathrm{O}^{+}(19,37,55,73)$ & $35(1), 53(1)$ & $1.9 \times 10^{-9}$ & Spanĕl\& Smith (2000) [14] \\
\hline Methanthiol & $\mathrm{H}_{3} \mathrm{O}^{+}(19,37,55,73)$ & $49(1), 67(1)$ & $2.5 \times 10^{-9}$ & Spanĕl\& Smith (1998b) [15] \\
\hline Ammonia & $\mathrm{O}_{2}^{+\cdot}(32)$ & $17(1), 35(1)$ & $2.4 \times 10^{-9}$ & Spaněl\& Smith (1998a) [13] \\
\hline Cadaverine & $\mathrm{H}_{3} \mathrm{O}^{+}(19.37,55,73)$ & $86(1), 103(1), 104(1)$ & $2.2 \times 10^{-9}$ & Ross et al. (2009) [16] \\
\hline Putrescine & $\mathrm{H}_{3} \mathrm{O}^{+}(19,37,55,73)$ & $89(2.1), 107(2.1)$ & $2.4 \times 10^{-9}$ & Ross et al. (2009) [16] \\
\hline Methanal & $\mathrm{H}_{3} \mathrm{O}^{+}(19,32)$ & $31(1), 33(-100.4), 83(-100.9)$ & $3.4 \times 10^{-9}$ & Spaněl\& Smith (2008) [17] \\
\hline Ethanal & $\mathrm{H}_{3} \mathrm{O}^{+}(19,37,55,73)$ & $45(1.576), 81(1.831)$ & $3.7 \times 10^{-9}$ & Spanĕl\& Smith (2008) [17] \\
\hline Propanal & $\mathrm{NO}^{+}(30,48)$ & $55(-0.006), 57(1.0)$ & $3.0 \times 10^{-9}$ & Spanělet al. (1997) [18] \\
\hline Butanal & $\mathrm{NO}^{+}(30,48)$ & $71(1)$ & $3.5 \times 10^{-9}$ & Spanĕlet al. (1997) [18] \\
\hline Pentanal & $\mathrm{NO}^{+}(30,48)$ & $85(1)$ & $3.2 \times 10^{-9}$ & Spanělet al. (1997) [18] \\
\hline Hexanal & $\mathrm{NO}^{+}(30,48)$ & $99(1)$ & $2.5 \times 10^{-9}$ & Spanělet al. (1997) [18] \\
\hline Heptanal & $\mathrm{NO}^{+}(30,48)$ & $113(1)$ & $3.1 \times 10^{-9}$ & Spanělet al. (1997) [18] \\
\hline Octanal & $\mathrm{NO}^{+}(30,48)$ & $127(1)$ & $3.0 \times 10^{-9}$ & Spanĕlet al. (1997) [18] \\
\hline Decanal & $\mathrm{NO}^{+}(30,48)$ & $155(1)$ & $3.3 \times 10^{-9}$ & Spanĕlet al. (1997) [18] \\
\hline
\end{tabular}

* Readers are referred to the referenced article for further details [12-18].

but LDA explicitly attempts to model the difference between the classes of data $[8,9]$.

Analyses of all data were carried out using the statistical software package StatView ${ }^{\circledR}$ 5.0 (SAS Inst., Cary, NC, USA). Descriptive statistics were calculated for the mean $\pm S D$ of physical and chemical measurements of biological samples of all participants. Mean parameter values of BC and HC groups were compared using two-tailed Student's $t$-test of significance. Differences were considered significant at $P<0.05$.

\section{Results}

High magnification histological photomicrographs at $100 x$ of malignant tissue samples for $B C$ patients, which shows infiltrating ductal carcinoma, low-grade with well-developed glands invading the fibrous stroma, as compared to benign tissue for $\mathrm{HC}$ participants, are shown in Figure 2. The demographic, clinical, and complete blood count (CBC) characteristics for BC patients and $\mathrm{HC}$ participants are shown in Table 2. BC diagnosis was associated with some known risk factors such as age, weight, BMI and familial history of BC. RBC counts and hemoglobin contents showed both $B C$ patients and $H C$ participants to be anemic. Moreover, $B C$ patients showed significantly higher $(P<0.001)$ tumor marker CA15-3 levels and WBC counts, yet significantly lower platelet counts, as compared to HC participants; although WBC and platelet counts were within normal ranges for the same age and sex for both groups. Women with close relatives who have been diagnosed with $B C$ had a higher risk of developing the disease.

The influence of $B C$ on headspace VOCs was studied in the urine, blood and tissue samples for both $B C$ patients and $H C$ participants. Being a confirmed BC patient of stage II was found to be directly related to average relative E-Nose 10-sensor responses for urine, as shown in Figure 1, and similarly for other blood and tissue samples. Figure 3 is a typical cluster-plot by LDA of urine, blood and tissue sample measurements using E-Nose for BC patients and HC participants. A clear distinction between both groups is evident, where both principal components \#1 and \#2 explained more than $98.84 \%$ of the variance in sensor-response signals, meaning that the E-Nose was capable of identifying samples from each group with no false-positive ( $\mathrm{HC}$ participants) or false-negative (BC patients) results. Meaning that the VOCs found in the urine, blood and tissue samples of $B C$ patients are significantly different from those for $\mathrm{HC}$ participants.

We studied the expression of 10-candidate alhdehyde VOCs in tissue specimens and blood samples of $B C$ patients and $\mathrm{HC}$ participants using SIFT-MS, as shown in Figure 4. Methanal, propanal, hexanal, heptanal and decanal levels in the headspace over $B C$ tissue specimens were significantly higher $(P<0.05)$, but pentanal and octanal were significantly lower, as compared to $\mathrm{HC}$ participants. Moreover, hexanal, nonanal and decanal levels in the headspace over BC blood samples 
Mohamed et al., Breast Cancer Reports 2017,

http://www.hoajonline.com/journals/pdf/2057-1631-4-3.pdf

doi: $10.7243 / 2057-1631-4-3$

Table 2. Demographic, clinical and complete blood count (CBC) characteristics of Healthy Control (HC) and Breast Cancer (BC) participant women.

\begin{tabular}{|c|c|c|c|c|}
\hline & & & Healthy Control & Breast Cancer \\
\hline Number & & & 150 & 150 \\
\hline Age (y) & & & $49.91 \pm 10.75$ & $51.12 \pm 10.35$ \\
\hline Weight (kg) & & & $73.12 \pm 4.24$ & $88.23 \pm 6.44^{*}$ \\
\hline Height (m) & & & $1.53 \pm 0.34$ & $1.55 \pm 0.36$ \\
\hline Body Mass Index $\left(\mathrm{kg} / \mathrm{m}^{2}\right)$ & & & $31.55 \pm 5.74$ & $36.23 \pm 4.14^{*}$ \\
\hline Haemoglobin (g/dl) & & & $11.14 \pm 2.21$ & $10.20 \pm 2.24$ \\
\hline Red Blood Cells $\times 10^{9} / \mathrm{L}$ & & & $3.41 \pm 0.24$ & $3.51 \pm 0.34$ \\
\hline White Blood Cells $\times 10^{6} / \mathrm{L}$ & & & $7.14 \pm 1.36$ & $9.01 \pm 2.11^{*}$ \\
\hline Platelets $\times 10^{9} / \mathrm{L}$ & & & $325.27 \pm 25.43$ & $210.14 \pm 35.44^{*}$ \\
\hline Tumor Marker CA 15-3 (U/mL) & & & -- & $55.22 \pm 44.42^{*}$ \\
\hline Breast Cancer Stage & & & -- & Grade II \\
\hline \multirow{2}{*}{ Estrogen Receptor (\%) } & & Yes & -- & 94 \\
\hline & & No & 6 & \\
\hline \multirow{2}{*}{ Progesterone Receptor (\%) } & & Yes & -- & 91 \\
\hline & & No & 9 & \\
\hline \multirow{6}{*}{ Breast Cancer Family History (\%) } & Yes & Father & -- & 5.72 \\
\hline & & Mother & -- & 8.61 \\
\hline & & Uncle & -- & 2.94 \\
\hline & & Sister & -- & 5.72 \\
\hline & & Niece & -- & 5.57 \\
\hline & No & & 100 & 71.44 \\
\hline \multirow{2}{*}{ Diabetes Type II (\%) } & & Yes & 2 & 16 \\
\hline & & No & 98 & 84 \\
\hline \multirow{2}{*}{ Hypertension (\%) } & & Yes & 20 & 38 \\
\hline & & No & 80 & 62 \\
\hline \multirow{3}{*}{\multicolumn{2}{|c|}{ Menstruation Status (\%) }} & Pre-menopause & 47.66 & 43.26 \\
\hline & & Menopause & 7.32 & 5.40 \\
\hline & & Post-menopause & 45.02 & 51.34 \\
\hline No. of Childbirth & & & $2 \pm 1$ & $3 \pm 2^{*}$ \\
\hline
\end{tabular}

${ }^{*} P<0.001$ as compared to Healthy Control participants

were significantly higher $(P<0.05)$, but methanal and pentanal were significantly lower, in comparison with $\mathrm{HC}$ participants. As such, pentanal, hexanal and decanal levels followed the same pattern of significant concentration changes in both blood and tissue headspace; the consistent and significant difference in expression of these VOCs in particular suggests their role to be used as differentiating tool for diagnosing BC.

The association between qualitative E-Nose sensor responses and quantitative SIFT-MS results for the aldehydes found in the headspace of tissue specimens and blood samples of both $\mathrm{BC}$ and $\mathrm{HC}$ participants is given in the correlation $(R)$ matrix of Table 3. Sensors \#1, 2, 4, 7 and 10 were significantly correlated with methanal, ethanal, propanal, butanal, pentanal, hexanal, and nonanal (i.e., $R>0.5, P<0.001$ for all associations) for both $\mathrm{HC}$ and $\mathrm{BC}$ tissue specimens. Moreover, $R$-values for $\mathrm{HC}$ and $B C$ blood samples associated with sensors \#1, 2, 4, 6, 7 , and 10 were significantly correlated with methanal, ethanal, propanal, butanal, pentanal, hexanal, nonanal, and decanal. According to the E-Nose manufacturer, sensors \#1, 2, 4, 7 and 10 are sensitive to $\mathrm{C}_{6} \mathrm{H}_{5} \mathrm{CH}_{3^{\prime}} \mathrm{NO}_{2^{\prime}} \mathrm{H}_{2^{\prime}} \mathrm{H}_{2} \mathrm{~S}$, and high concentrations (>100 mg/kg) of methane-aliphatic compounds; respectively.

\section{Discussion}

BC is usually epithelial tumor of ductal or lobular origin. Size of the breast tumor, status of surgical margin, presence or absence of estrogen receptors and progesterone receptors, nuclear and histological grade, DNA content, s-phase fraction, vascular invasion, tumor necrosis, and quantity of 

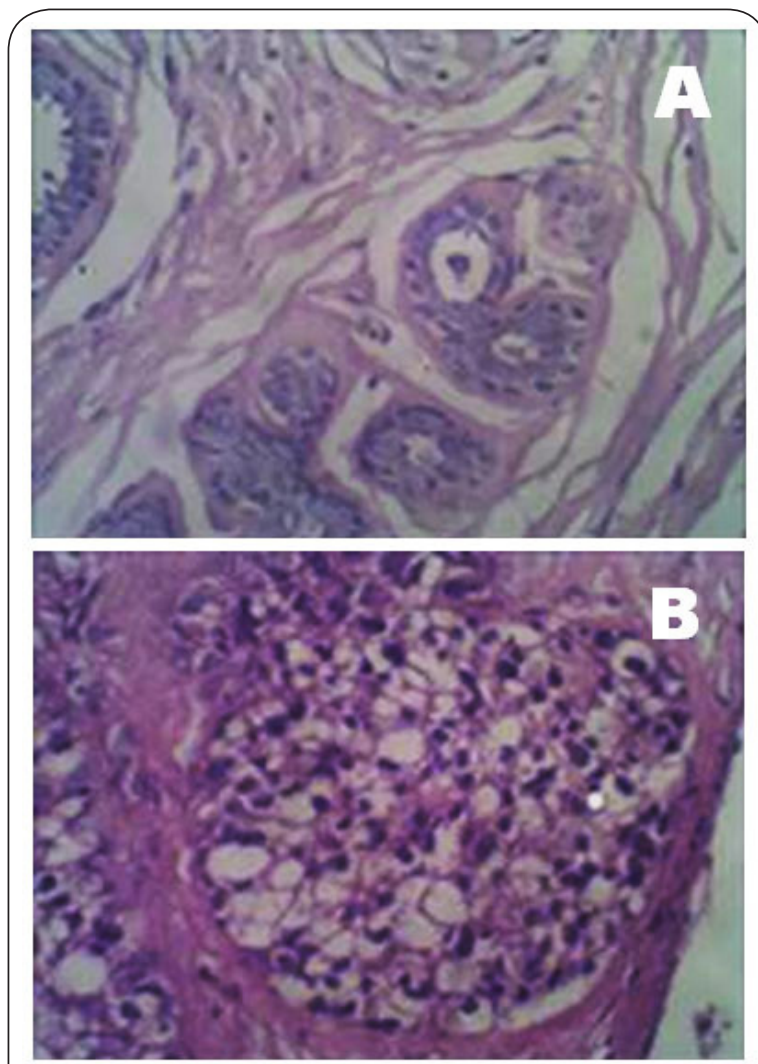

Figure 2. High magnification histological photomicrograph at 100x of a benign tissue sample for Healthy Control (HC) participant (A) and a malignant tissue for Breast Cancer (BC) patient (B).

intraductal component are all-important for deciding on a course of treatment. BC has been found to be associated with some known risk factors such as older age, increased weight and $\mathrm{BMI}$, and familial history of $\mathrm{BC}[\mathbf{2 0 , 2 1 ]}$. Weight and BMI were significantly different between $B C$ patients, who were obese to morbidly obese with an average BMI of $36.23 \pm 4.14$ $\mathrm{kg} / \mathrm{m}^{2}$, and $\mathrm{HC}$ females, who were overweight to obese with an average BMI of $31.55 \pm 5.74 \mathrm{~kg} / \mathrm{m}^{2}$. Meaning that, females with higher-grade obesity exhibit an increased risk for developing BC, which can be attributed to the contribution of fat tissue increasing estrogen levels that may elevate the risk of developing BC [20].

Overweight and obesity have been shown to be associated with a modest increase in risk of post-menopausal BC, who express both estrogen and progesterone receptors [20]. About $98 \%$ of our patients were positive to estrogen receptors and $91 \%$ were positive to progesterone receptors, suggesting a role for the hormonal imbalance associated with the post-menopausal status. On the other hand, obesity was shown to play a protective effect against developing $B C$ in pre-menopausal females [20], while other studies have shown no association between obesity and BC risk [21].

This discrepancy may have several explanations, including

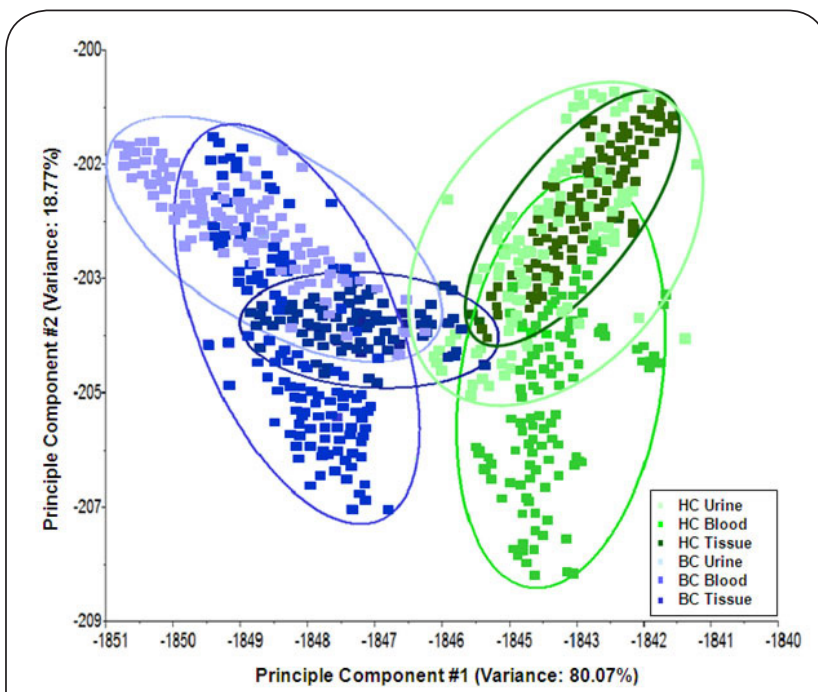

Figure 3. Scatter-plot of principal component \#1 against principal component \#2 for an array of 10 metal-oxide sensors based Electronic Nose (E-Nose) when applied to the head space of urine, blood and tissue samples from Breast Cancer (BC) patients and Healthy Control (HC) participants.

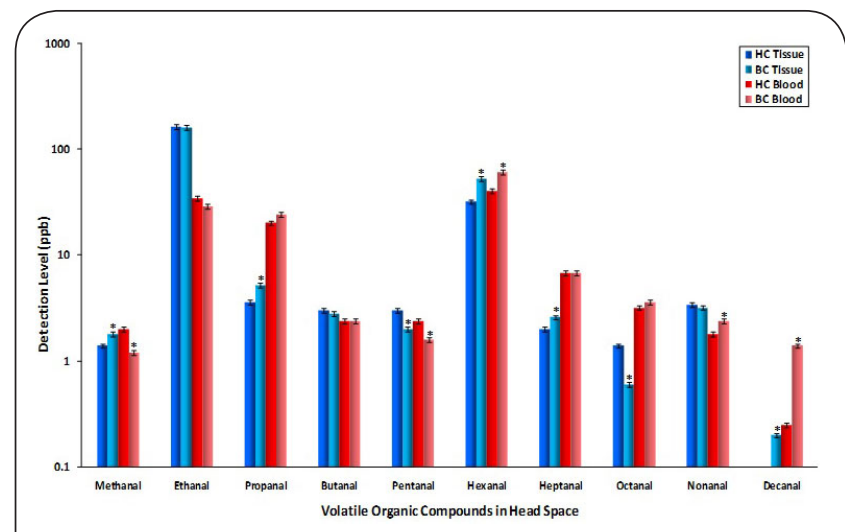

Figure 4. Expression of volatile organic compounds (VOCs) found in the headspace of both tissue specimens and blood samples of Breast Cancer (BC) patients and Healthy Control (HC) participants using Selected Ion Flow Tube-Mass Spectrometry (SIFT-MS). Differences are statistically significant at $P<0.05$ as compared to $\mathrm{HC}$ using a $t$-test between $\mathrm{BC}$ and $\mathrm{HC}$ groups.

the implication of genetic and/or environmental factors in the obesity-related development of the disease or physical inactivity [22]. In fact, family history is considered an important risk factor for developing $\mathrm{BC}$, which reflects the role of genetic and epigenetic modifications at important genes such as BRCA1 and BRCA2 in the predisposition to the disease [23]. We found that women with a positive family history of $B C$, with prevalence among mothers of patients, had BC (Table 2). This agrees with what had been previously reported in various populations in different geographical regions [23]. High parity has generally been associated with low $B C$ risk in 


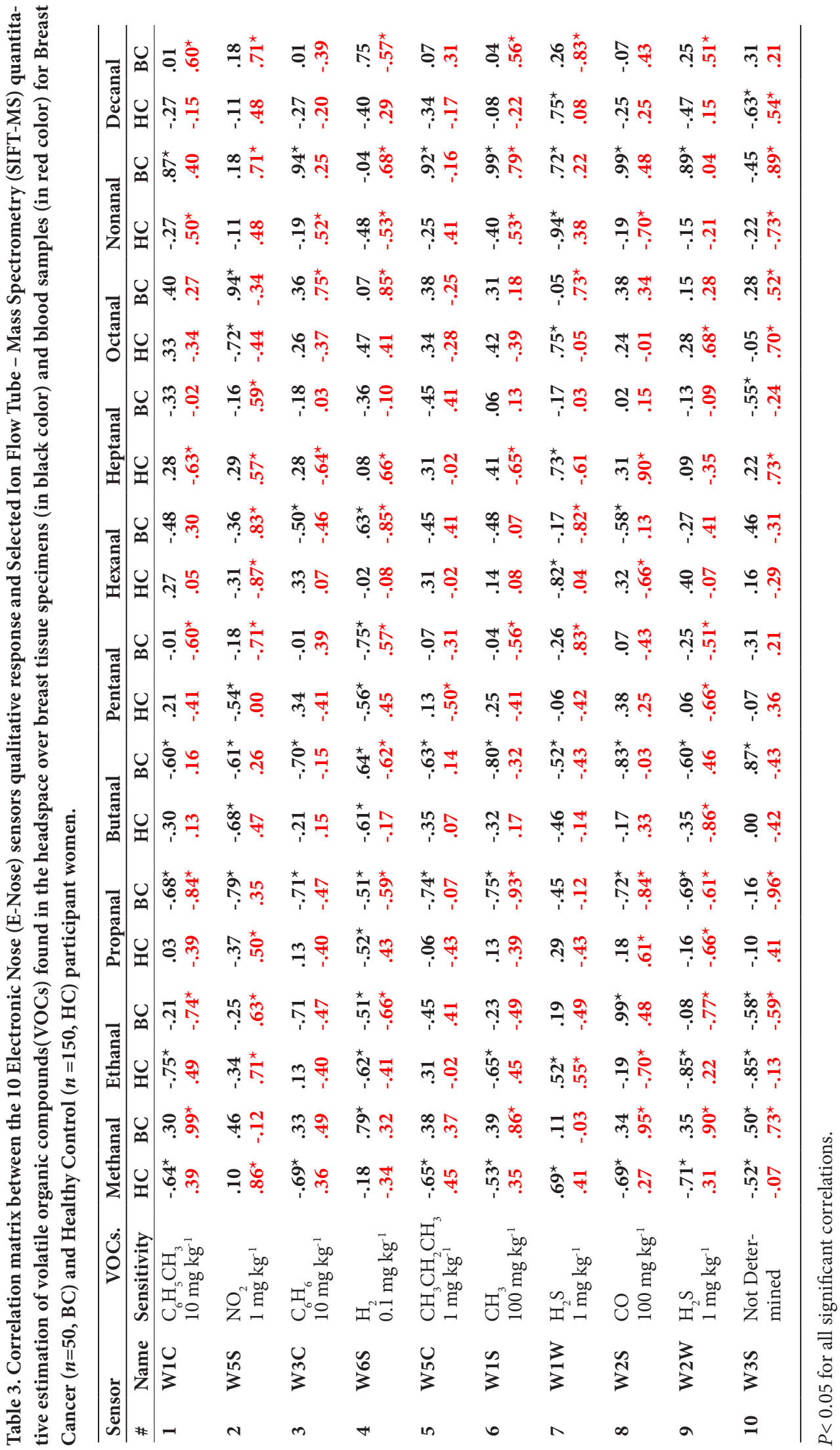


previous epidemiological studies. Null parity was associated with an overall increased risk of BC. Contradictory to those studies, we have found that many women presented with $B C$ despite of high parity, which agrees with a previous study conducted on Indian women by Surakasula et al. [24], who showed similar findings.

Post-menopausal status showed the highest frequency among $B C$ women in this study. It was hypothesized that post-menopausal women have a higher risk of $B C$ than pre-menopausal women of the same age and childbearing pattern. Risk increases by almost 3\% for each year older at menopause (natural or surgery induced), thus women who had attained menopause at 55 years rather than 45 years, had approximately $30 \%$ higher risk [25]. The majority of participant women in this study reached menopause after the age of 45 years. Risk of developing BC increased in both pre- and post-menopausal patients who had early onset of menarche and late menopause, possibly due to the increase in the duration of hormonal exposure [21,24]. As such, even though there are many risk factors for $\mathrm{BC}$, many replicated by us, none predicts with certainty who will contract the disease or when it will occur. The need for better diagnostic or screening tests therefore remains, with the E-Nose VOCs analysis being a promising means for this purpose, given it is safe, non-invasive, potentially fast and inexpensive.

A number of VOCs, such as alkanes, aromatic compounds and benzene derivatives, had been identified using gas chromatography-mass spectroscopy (GC-MS) in the exhaled breath of patients with different non-respiratory diseases (e.g., $\mathrm{BC}$, heart transplant rejection, heart failure, diabetes and preeclampsia) $[\mathbf{9 , 2 6}]$. In this study, we focused on either aldehydes mainly due to the SIFT-MS technique's limited applicability to alkanes, or to the undefined compounds, which influence E-Nose response. The mechanisms, through which aldehydes metabolites are generated, continue to be explored, and no unified consensus has been reached. However, the majority of relevant experimental results support the idea that these compounds result from oxidative stress [6]. Tumor tissues are characterized by vigorous growth and high energy demands. That is, histological investigations of breast biopsies in this study (Figure 2) showed BC tissues of increased cellularity, increased number of mitotic signs, and extension of sclerotic areas, morphological changes of cell nuclei, DNA fragmentation, and distended duct with intact basement membrane and appearance of some necrotic signs. The malignant growth processes of cancer cells can lead to gene mutations and protein expression abnormalities. As a result, polyunsaturated fatty acids in cell membranes are subject to excessive oxidation, and an individual may produce excessive reactive oxygen species. In addition, reductions in other chemicals may result from the consumption of these substances by tumor cells. The specific biological mechanisms that generate volatile metabolites remain under investigation [6].

Notably, both BC and HC groups studied showed a num- ber of aldehyde concentration changes in tissue specimens and blood samples headspace (see Figure 3). Adding that, hexanal was found to be commonly changed between both groups, as was propanal, the major peroxidation products of omega- 6 and omega- 3 polyunsaturated fatty acids respectively, findings that were supported earlier by Frankel et al. [27]. However, propanal concentrations were not altered in blood headspace while the concentrations of other aldehydes were altered in ways differing from that of tissue. Pentanal, hexanal, and decanal changed similarly in both tissue and blood headspace making the possibility that these aldehydes are actual cancer biomarkers more likely.

These results are also in line with findings by Philips et al. [26], who investigated the abundance of methylated alkanes in the breath of females with and without histologically proven $B C$ and healthy volunteers. They have shown that breath VOCs markers of oxidative stress were characteristic to $B C$ and that they were either increased or decreased in abundance due to either an increased oxidative stress mechanism, or an increased cytochrome P-450 activity, respectively. Furthermore, BC is accompanied by both increased oxidative stress and induction of cytochrome P-450 mixed oxidase enzymes, either because oxidative stress causes lipid peroxidation, thereby producing and increasing alkanes and methylalkanes, or because the associated induction of enzyme activities may increase their rate of catabolism by relevant cytochrome P-450 isoforms.

In addition, Subramanian et al. [28] have hypothesized that the volatile biomarkers of $\mathrm{BC}$ relate to changes in estrogen metabolism mechanisms. This notion is supported by the fact that estrogen stimulation can stimulate the proliferation of both normal and neoplastic mammary epithelial cells. Investigations have also revealed that abnormally high aromatase expression occurs in BC tissues [28]. Aromatase (estrogen synthetase) is a component of the cytochrome P-450 (CYP) enzyme complex that converts $\mathrm{C} 19$ androgen to $\mathrm{C} 18$ estrogen, thereby increasing estrogen generation. Other $\mathrm{P}-450$ enzymes are also activated in BC tissues, such as CYP1A1, CYP1B1 and CYP3A4. P-450 can induce a wide variety of biological response, including promotion of the biotransformation of alkanes, alkenes, and aromatic compounds [29]. The metabolism of normal body cells can generate certain volatile metabolites, such as alkanes, that are produced because of oxidative stress. Given the multitude of P-450 functions, the elevated activity of this enzyme in $B C$ tissues may markedly alter the components of exhaled air. Jongen et al. [29] have also suggested that BC is associated with increases in oxidative stress and elevated cytochrome P-450 activity.

Estrogen and changes in its metabolism mechanisms play a crucial role in the carcinogenic processes of BC. Spink et al. [30], reported that cytochrome P-450 1B1 catalyzes the conversion of estrogen to 4-hydroxyestradiol (4-OH-E2), which is a main driver of carcinogenic mechanisms in $\mathrm{BC}$ tissues. It has been shown that the ratio of 4-OH-E2 to 2-hydroxyestradiol (2-OH-E2) is significantly higher in BC tissue than in normal 
Mohamed et al., Breast Cancer Reports 2017,

http://www.hoajonline.com/journals/pdf/2057-1631-4-3.pdf

breast tissue. Estrogen metabolites can promote carcinogenesis by damaging cellular macromolecules and promoting the proliferation of injured cells through receptor-mediated processes. Changes in estrogen metabolism can generate certain distinct VOCs, findings that agree with our results of positive estrogen and progesterone receptors in $\mathrm{BC}$ women.

Average E-Nose sensor responses, especially those sensitive towards $\mathrm{C}_{6} \mathrm{H}_{5} \mathrm{CH}_{3^{\prime}}, \mathrm{NO}_{2^{\prime}} \mathrm{H}_{2^{\prime}}, \mathrm{H}_{2} \mathrm{~S}$, and high concentrations of methane-aliphatic compounds; respectively, were found to correlate highly with many aldehydes quantified by SIFT-MS (see Table 3). Such correlations were unexpected, suggesting a low specificity of the E-Nose response, despite the manufacturers'specifications of the identity of the compounds that each sensor responds to, that they may well be responding to oxidative stress markers such as aldehydes, as opposed to less biologically plausible marker compounds such as $\mathrm{H}_{2}$ or $\mathrm{C}_{6} \mathrm{H}_{5} \mathrm{CH}_{3}$. Indeed, it can be considered a point of strength of the $\mathrm{E}-$ Nose that it can differentiate $\mathrm{BC}$ without knowing the identity of specific chemical composition, although in such uncertainty lies the possibility of artifactual effects like unexpected influences of ambient air trace gases. That aside, the E-Nose technique also suggests the utility of VOCs analysis for $\mathrm{BC}$ diagnosis, in this case using a method much simpler and less costly than SIFT-MS.

\section{Conclusion}

Early diagnosis of $B C$ is a desirable goal for decreasing the disease burden and providing good prognosis. The analysis of VOCs associated with cancer is a new frontier in medical diagnostics, since it is non-invasive and potentially inexpensive. Whatever the biological mechanisms at play in altering the VOCs released from tumors, our data strongly suggest that this change may have use in identifying BC. Hexanal in particular appears to be of potential use. Given that the diagnosis of our participants was not in doubt, future prospective studies using currently healthy women who are 'at risk' of developing $B C$ are needed to determine whether VOCs analysis will allow the disease to be diagnosed in the pre-symptomatic stage when it is most easily treated.

\section{List of abbreviations}

ASR: Age-Standardized Rate;

$\mathrm{BC}$ : Breast Cancer;

BMI: Body Mass Index;

$\mathrm{C}_{6} \mathrm{H}_{5} \mathrm{CH}_{3}$ : Toluene;

CA15-3: Tumor Marker CA15-3;

CBC: Complete Blood Count;

CYP: Cytochrome P-450;

E-Nose: Electronic Nose;

$\mathrm{H}_{2}$ : Hydrogen;

$\mathrm{H}_{2} \mathrm{~S}$ : Hydrogen Sulfide;

$\mathrm{HC}$ : Healthy Controls;

LDA: Linear Discriminant Analysis;

$\mathrm{NO}_{2}$ : Nitrogen Dioxide;

PCA: Principal Components Analysis;

PPBV: Parts Per Billion Volume;

PPTV: Parts Per Trillion Volume;
RBC: Red Blood Cells;

SIFT-MS: Selected Ion Flow Tube-Mass Spectrometry;

VOCs: Volatile Organic Compounds;

WBC: White Blood Cells

\section{Competing interests}

The authors declare that they have no competing interests.

Authors' contributions

\begin{tabular}{|l|c|c|c|c|c|c|c|}
\hline Authors' contributions & EIM & MHM & MAM & SIA & HKM & TWG & BMR \\
\hline $\begin{array}{l}\text { Research concept and } \\
\text { design }\end{array}$ & $\checkmark$ & -- & -- & $\checkmark$ & -- & -- & $\checkmark$ \\
\hline $\begin{array}{l}\text { Collection and/or } \\
\text { assembly of data }\end{array}$ & $\checkmark$ & $\checkmark$ & $\checkmark$ & -- & -- & $\checkmark$ & -- \\
\hline $\begin{array}{l}\text { Data analysis and } \\
\text { interpretation }\end{array}$ & $\checkmark$ & $\checkmark$ & $\checkmark$ & $\checkmark$ & $\checkmark$ & $\checkmark$ & $\checkmark$ \\
\hline Writing the article & $\checkmark$ & $\checkmark$ & $\checkmark$ & -- & -- & $\checkmark$ & $\checkmark$ \\
\hline $\begin{array}{l}\text { Critical revision of the } \\
\text { article }\end{array}$ & $\checkmark$ & -- & -- & -- & -- & -- & $\checkmark$ \\
\hline Final approval of article & $\checkmark$ & $\checkmark$ & $\checkmark$ & $\checkmark$ & $\checkmark$ & $\checkmark$ & $\checkmark$ \\
\hline Statistical analysis & $\checkmark$ & $\checkmark$ & -- & -- & -- & -- & -- \\
\hline
\end{tabular}

\section{Acknowledgement}

The authors would like to express their deepest gratitude to all participant breast cancer patients, and their relatives, at the Medical Research Institute, Alexandria University,

Alexandria, Egypt.

Publication history

Editor: Jianxun Song, Penn State University College of Medicine, USA. Received: 09-Apr-2017 Final Revised: 07-Jun-2017

Accepted: 19-Jul-2017 Published: 26-Jul-2017

\section{References}

1. Mohamed El, Abdel-Mageed SM, Khalil GI, Emara AM, Ramadan HS and Abd El-Moneim NA. Effect of Adjuvant Chemotherapy on Cross-Linked Carboxytelopeptide of Type I Collagen of Egyptian Women with NonMetastatic Breast Cancer. Breast Canc Rep. 2014; 1:1-7.

2. Azim HA and Ibrahim AS. Breast cancer in Egypt, China and Chinese: statistics and beyond. J Thorac Dis. 2014; 6:864-6. | Article | PubMed Abstract | PubMed FullText

3. Khazaei S, Rezaeian S, Khazaei Z, Molaeipoor L, Nematollahi S, Lak P and Khazaei $S$. National breast cancer mortality and incidence rates according to the human development index: an ecological study $A d v$ Breast Can Res. 2016; 5:30-6.

4. Ibrahim AS, Khaled HM, Mikhail NN, Baraka H and Kamel H. Cancer incidence in egypt: results of the national population-based cancer registry program. J Cancer Epidemiol. 2014; 2014:437971. | Article | PubMed Abstract | PubMed FullText

5. Thomson CS, Hole DJ, Twelves CJ, Brewster DH and Black RJ. Prognostic factors in women with breast cancer: distribution by socioeconomic status and effect on differences in survival. J Epidemiol Community Health. 2001; 55:308-15. | Article | PubMed Abstract | PubMed FullText

6. Barrera G. Oxidative stress and lipid peroxidation products in cancer progression and therapy. ISRN Oncol. 2012; 2012:137289. | Article | PubMed Abstract I PubMed FullText

7. Peng G, Hakim M, Broza YY, Billan S, Abdah-Bortnyak R, Kuten A, Tisch U and Haick $\mathrm{H}$. Detection of lung, breast, colorectal, and prostate cancers from exhaled breath using a single array of nanosensors. Br J Cancer. 2010; 103:542-51. | Article | PubMed Abstract | PubMed FullText

8. Mohamed El, Mahmoud GN, El-Sharkawy RM, Moro AM, Abdel-Mageed SM and Kotb MA. Electronic nose for tracking different types of leukaemia: future prospects in diagnosis. Hematol Oncol. 2014; 32:165- 
Mohamed et al., Breast Cancer Reports 2017,

\section{7. | Article | PubMed}

9. Mohamed El, Khalil GI, Abdel-Mageed SM, Bayoumi AM, Ramadan HS and Kotb MA. Electronic noses for monitoring benzene occupational exposure in biological samples of Egyptian workers. Int J Occup Med Environ Health. 2013; 26:165-72. | Article | PubMed

10. Amadei $G$ and Ross $B M$. The reactions of a series ofterpenoids with $\mathrm{H}_{3} \mathrm{O}^{+}, \mathrm{NO}^{+}$and studied using selected ion flow tube mass spectrometry. Rapid Commun Mass Spectrom. 2011; 25:162-8.

11. Spanel $P$ and Smith D. Selected ion flow tube mass spectrometry for on-line trace gas analysis in biology and medicine. Eur J Mass Spectrom (Chichester). 2007; 13:77-82. | Article | PubMed

12. Spanĕl P and Smith D. SIFT studies of the reactions of $\mathrm{H}_{3} \mathrm{O}^{+}, \mathrm{NO}^{+}$and $\mathrm{O}_{2}^{+}$ with a series of alcohols. Int J Mass Spectrom. 1997; 167/168:375-88.

13. Spanĕl $P$ and Smith D. SIFT studies of the reactions of $\mathrm{H}_{3} \mathrm{O}^{+}, \mathrm{NO}^{+}$and $\mathrm{O}_{2}^{+}$ with a series of volatile carboxylic acids and esters. Int $J$ Mass Spectrom. 1998a; 172:137-47.

14. Spanel $P$ and Smith D. Quantification of hydrogen sulphide in humid air by selected ion flow tube mass spectrometry. Rapid Commun Mass Spectrom. 2000; 14:1136-40. | Article | PubMed

15. Spanĕl P and Smith D. SIFT studies of the reactions of $\mathrm{H}_{3} \mathrm{O}^{+}, \mathrm{NO}^{+}$and $\mathrm{O}_{2}^{+}$with some organosulphur molecules. Int J Mass Spectrom. 1998b; 176:167-76.

16. Ross BM, Babay $S$ and Ladouceur $C$. The use of selected ion flow tube mass spectrometry to detect and quantify polyamines in headspace gas and oral air. Rapid Commun Mass Spectrom. 2009; 23:3973-82. | Article I PubMed

17. Spanel P and Smith D. Quantification of trace levels of the potential cancer biomarkers formaldehyde, acetaldehyde and propanol in breath by SIFT-MS. J Breath Res. 2008; 2:046003. | Article | PubMed

18. Spanĕl $P$, Ji $Y$ and Smith D. SIFT studies of the reactions of $\mathrm{H}_{3} \mathrm{O}^{+}, \mathrm{NO}^{+}$and $\mathrm{O}_{2}^{+}$with a series of aldehydes and ketones. Int J Mass Spectrom. 1997; 165/166:25-37.

19. Ross BM, Puukila S, Malik I, Babay S, Lecours M and Agostino A et al. The use of SIFT-MS to investigate headspace aldehydes as markers of lipid peroxidation. CurrAnalyt Chem. 2013; 9(4):600-13.

20. Amadou $A$, Hainaut $P$ and Romieu I. Role of obesity in the risk of breast cancer: lessons from anthropometry. J Oncol. 2013; 2013:906495. I Article | PubMed Abstract | PubMed FullText

21. Neuhouser ML, Aragaki AK, Prentice RL, Manson JE, Chlebowski R, Carty CL, Ochs-Balcom HM, Thomson CA, Caan BJ, Tinker LF, Urrutia RP, Knudtson J and Anderson GL. Overweight, Obesity, and Postmenopausal Invasive Breast Cancer Risk: A Secondary Analysis of the Women's Health Initiative Randomized Clinical Trials. JAMA Oncol. 2015; 1:61121. | Article | PubMed Abstract | PubMed FullText

22. Mabry RM, Reeves MM, Eakin EG and Owen N. Evidence of physical activity participation among men and women in the countries of the Gulf cooperation council: a review. Obes Rev. 2010; 11:457-64. | Article I PubMed

23. El-Harith el HA, Abdel-Hadi MS, Steinmann D and Dork T. BRCA1 and BRCA2 mutations in breast cancer patients from Saudi Arabia. Saudi Med J. 2002; 23:700-4. | PubMed

24. Surakasula A, Nagarjunapu GC and Raghavaiah KV. A comparative study of pre- and post-menopausal breast cancer: Risk factors, presentation, characteristics and management. J Res Pharm Pract. 2014; 3:12-8. Article | PubMed Abstract | PubMed FullText

25. Butt Z, Haider SF, Arif S, Khan MR, Ashfaq U, Shahbaz U and Bukhari MH. Breast cancer risk factors: a comparison between pre-menopausal and post-menopausal women. J Pak Med Assoc. 2012; 62:120-4. | Article | PubMed

26. Phillips M, Cataneo RN, Ditkoff BA, Fisher P, Greenberg J, Gunawardena $R$, Kwon CS, Rahbari-Oskoui F and Wong C. Volatile markers of breast cancer in the breath. Breast J. 2003; 9:184-91. | PubMed

27. Frankel EN, Parks EJ, Xu R, Schneeman BO, Davis PA and German JB. Effect of $n-3$ fatty acid-rich fish oil supplementation on the oxidation of low density lipoproteins. Lipids. 1994; 29:233-6. | PubMed

28. Subramanian A, Salhab M and Mokbel K. Oestrogen producing enzymes and mammary carcinogenesis: a review. Breast Cancer Res Treat. 2008; 111:191-202. | Article | PubMed

29. Jongen VH, Hollema H, Van Der Zee AG and Heineman MJ. Aromatase in the context of breast and endometrial cancer. A review. Minerva Endocrinol. 2006; 31:47-60. | PubMed

30. Spink DC, Hayes CL, Young NR, Christou M, Sutter TR, Jefcoate CR and Gierthy JF. The effects of 2,3,7,8-tetrachlorodibenzo-p-dioxin on estrogen metabolism in MCF-7 breast cancer cells: evidence for induction of a novel 17 beta-estradiol 4-hydroxylase. J Steroid Biochem Mol Biol. 1994; 51:251-8. | PubMed

\section{Citation:}

Mohamed EI, Moustafa MH, Mohamed MA, Awad E-SI, Maghraby HK, Godeto TW and Ross BM. Qualitative and quantitative analysis of biological samples from non-metastatic breast cancer patients. Breast Cancer Rep. 2017; 4:3.

http://dx.doi.org/10.7243/2057-1631-4-3 